\title{
EDITORIAL
}

\section{UN SECURITY COUNCIL RESOLUTION 1325 AND THE ROLE OF GENDER PERSPECTIVE}

An increasingly intensive activity has been noticed recently at the international level with regard to the implementation of United Nations Security Council Resolution 1325 and associated resolutions. More and more international events regarding women, peace and security are being organised every year, education and training programmes as well as a conceptual framework of the gender perspective are being developed, and system solutions in both international organisations and national structures are being put forward. One of such solutions is the appointment of ambassadors for women, peace and security, as well as of gender advisors on gender perspective. Last year, a full-time advisor position in this field was set up at the General Staff of the Slovenian Armed Forces. Being a subject matter expert for the area of gender perspective in the Slovenian Armed Forces, I am pleased that the importance of the agenda regarding women, peace and security has been recognised and that a publication has been issued at the academic level by involving experts and gaining support from the leadership. I am grateful to my international colleagues for their papers, for having kindly responded to the invitation to share their views, solutions and experiences with us. This is indeed the main value of this publication: sharing is caring. The set of topics demonstrates to what extent the Resolution and the gender perspective are implemented, ranging from the international level, through national solutions and to the realisation in international operations and missions.

Although Resolution 1325 is extensively explained in individual papers, I would like to introduce several key factors linking the Resolution and the gender perspective, to proffer a better understanding of the topic and emphasise why the integration of the gender perspective is vital for both Slovenian and international landscape. The basis for this discussion are conceptual solutions of international organisations and my participation in the NATO Committee on Gender Perspectives. Actions like this are vital for they aim to develop the said area and encourage new ways of thinking, 
thereby highlighting compound gender-related topics and informing the practices of Slovenian Armed Forces.

Resolution 1325 is a milestone for the role of women in conflict prevention and resolution, in peace processes, humanitarian response and in post conflict reconstruction. It underlines three interlinking factors, i.e. women, peace and security. There is no security without peace, and no peace without a safe and secure environment. Moreover, there is no peace and security without addressing the entire population. In the past, women were frequently excluded from peace processes. If solely one perspective is included, the expected result can be partial.

In 15 years since the adoption of Resolution 1325, the increased asymmetric threats in a complex security environment have resulted in the need for more comprehensive approaches to ensure security and peace around the world. During this time, many facts which were ignored in the past have been seriously discussed at the international level with the aim of finding solutions. Armed conflicts and the post-conflict period affect women differently than men. Boys and girls too are affected differently, in relative terms. Importantly, acts of men and women in such circumstances can be either different or the same, but due to socially constructed perceptions they are accepted differently. More particularly, it should be stressed that socially constructed is their gender, which is a concept that this introduction defines as social and cultural characteristics associated with a given sex (whereas sex refers to biological differences between males, females, and intersex persons, and is assigned at birth).

Gender as such materialises in our reality: for example, while during armed conflicts the majority of men are recruited for combat tasks, women stay at home with children or are forced to leave their homes. That is why they make up the majority of internally displaced persons and refugees both on refugee routes and in refugee camps. Their safety is compromised in such circumstances; they are often targeted by groups of combatants, kidnapped, enslaved or abused. It should also be noted that girls and boys are not exposed in the same way: girls can be subject to premature and forced marriages, boys to early recruitment into combatant groups. As regards the general recognition of the role of men and women in armed conflicts and beyond, the most common perception is of women as victims and men as combatants. However, the truth is that women also are combatants and strong actors for peace, and men are victims of intentionally committed acts. Furthermore, a serious problem in contemporary conflicts is sexual and gender-based violence. This is an alarming issue. This form of violence is predominantly inflicted against women, although also girls, boys and men suffer from it, either in the form of torture or as a weapon of war.

It could be said that the gender perspective in relation to international operations and missions has, on the one hand, developed for the purpose of implementing Resolution 1325 and, on the other hand, resulted from militaries' experiences. Central to the gender perspective in international operations and missions is making women's and men's experiences and concerns integral to operation processes, whilst 
taking into account the different security-related situations these individuals face in line with their gender. As it has been argued, there is evidence that women and men, boys and girls, face different security risks - a process underpinned by the way their masculinities and femininities are perceived in a given culture and society, i.e. gender. Being able to recognise and understand the entire security situation as broadly as possible is crucial for operational effectiveness. Recognising the routes of women, which are usually different from routes used by men due to their individual gender roles, can affect the execution of an operation. Such information influences the provision of security, force protection and operational success.

Therefore, the integration of the gender perspective into every process at all levels and in every stage of action is of extreme importance; comprehensive information on situation in the area of operation contribute to decisions of those in command. Experiences gained in international operations and missions have led to observations on certain limitations in the execution of tasks, particularly at the tactical level, for example as regards the exclusion of women from the local environment, particularly in those areas of operation where women are not allowed to communicate publicly with unknown men and where the structure and personnel are predominantly male. The inclusion of the gender perspective into task accomplishment has thus become a necessity to which international organisations, such as UN, NATO, the EU and other have drawn attention.

In their structures, the contemporary armed forces need both female and male members at all levels and on different duties. This holds true for the fulfilment of tasks in international operations and missions and for the execution of tasks in domestic environment. International organisations tend to increasingly emphasize the importance of the inclusion of women into all structures; however, questions regarding women in armed forces keep appearing in the military, particularly as regards gender equality, physical performance of women and removal of restrictions in relation to the fulfilment of certain duties for women. There are growing tendencies to implement the gender equality principle, whereby a risk of equating equality with sameness may appear in the militaries.

However, to perceive equality as sameness can lead to unilateral or too general solutions. Concerns, for example, that taking into account the biological differences between men and women in setting the standards could mean lower criteria and poorer performance actually lead to more important question: are standards really defined according to the requirements of individual duties or are they too general, and are they also established on the basis of the inclusion of gender perspective? It is crucial to understand that different tasks require different competences and preparedness of an individual. Indeed, the truth is that men and women will never be the same. There is variety between males and females which should be recognised as an advantage and not as a weakness. Failing to include the spectrum of gender, the wholeness cannot be reached; the inclusion of both male and female perspective on the same issue leads to integrity by bringing together the diversity. 
Due to changing security environment, we all are faced with new challenges, requiring even stronger networking of organisations both at the national and international levels in order to ensure comprehensive and effective solutions. Meteorological changes causing large-scale destruction call more often for the engagement of the armed forces in search and rescue tasks. Last year, mass migration from conflict zones, the Middle East and Africa to Europe required the involvement of the armed forces into tasks at home. Similarly as in fulfilling the tasks in international operations and missions, the armed forces and other government and non-government organisations dealing with refugees and migrants were faced with different cultures, where socially determined roles of men and women have great significance. Such circumstances promote further knowledge about the integration of gender perspective in new directions. The fundamental fact that the society is made up of women and men, girls and boys, remains, just as the diversity which, in its integrity, should bring us all towards ensuring security and peace.

I wish you a pleasant reading of papers hoping they will help broaden new horizons and encourage new thoughts. 